\title{
Asperger Syndrome
}

National Cancer Institute

\section{Source}

National Cancer Institute. Asperger Syndrome. NCI Thesaurus. Code C97159.

A disorder most often diagnosed in the pediatric years in which the individual displays

marked impairment in social interaction and a repetitive, stereotyped pattern of behavior.

The individual, however, displays no delay in language or cognitive development, which differentiates Asperger Syndrome from autism. 